\title{
Peripheral intravenous catheter use in Europe: towards the use of safety devices
}

\author{
K. W. Strauss ${ }^{1,2}$, R. Onia ${ }^{3}$, and A. A. J. van Zundert ${ }^{4,5}$ \\ ${ }^{1}$ European Medical Association, Brussels, Belgium, ${ }^{2}$ POB 13, Erembodegem-Dorp 86, B-9320 Erembodegem-Aalst, Belgium, ${ }^{3}$ The Danby \\ Building, Oxford, UK, ${ }^{4}$ Catharina Hospital-Brabant Medical School, Department of Anesthesiology, ICU E Intensive Care, Eindhoven, the \\ Netherlands, ${ }^{5}$ University Hospital, Ghent, Belgium
}

Background: Peripheral intravenous catheters are among the most widely used medical devices in the world. European patients are increasingly aware of the risk of health care associated infections and the role catheters play in their facilitation.

Aims: We intend to show that European health care providers are increasingly aware of the occupational risks of bloodborne infections such as HIV and hepatitis which can be transmitted by the needles from catheters and that the political will is building to take action to ensure safer devices are provided.

Methods: We review the wide variety of peripheral intravenous catheters which are specially engineered to reduce these risks.
Results: Available safety devices include spring-loaded retractable needles, guards that shield the dangerous tips and closed, needle-free access valves for intravenous sets. Conlusions: It is no longer necessary for patients and professionals to take risks to health and life when solutions which minimize these risks are at hand.

Accepted for publication 8 February 2008

Key words: Intravenous catheters; complications; safety devices.

(C) 2008 The Authors

Journal compilation (C) 2008 The Acta Anaesthesiologica Scandinavica Foundation
$\mathrm{T}$ HE intravenous catheter (IVC) is one of the most ubiquitous medical devices in the world. Approximately four out of five hospitalised patients have an IVC inserted at some point during their stay (1). We have already described the history of this remarkable device (2) and have provided guidelines as to best practice regarding its use in the individual patient (3). In this paper we propose exploring the variety of peripheral IVC devices and their distribution in Europe, a region that has long played a leadership role in introducing medical innovations to the world.

\section{History}

The concept of the IVC is seductively simple. The original 'Rochester needle', the brainchild of Dr David Massa, an anaesthetist at the Mayo Clinic (4, $5)$, was merely a larger needle slipped over a smaller one. The larger needle penetrated the vessel, making room for the smaller one to be slid in. The latter was soon replaced with a plastic catheter because polyvinyl chloride was obviously less traumatic to vessels. It was soon discovered that the plastic element could fit over the outside of the needle and still slip effortlessly into the vein. These landmark inventions occurred over a remarkably short period of time in the 1950s and are credited to clinicians at Mayo as well as scientists working at the medical companies Deseret (Sandy, UT) and BD (Franklin Lakes, NJ).

Since then, the variety of IVCs and their applications have expanded at a dizzying pace (Fig. 1).

Today, there are peripheral IVCs $(<2 \mathrm{~cm}$, inserted into veins of the upper extremities), central IVCs (usually longer than $10 \mathrm{~cm}$, inserted into large veins which arise proximal to the axilla and empty into the central circulation) and peripherally inserted central catheters (usually longer than $20 \mathrm{~cm}$, inserted into large arm or groin veins and then threaded into the central venous circulation). Devices used for arterial cannulation, dialysis fistula insertion and implanted chamber access also use the same basic template as the peripheral IVC.

Some peripheral IVCs have a secondary port near the insertion site for drawing blood or giving 
Fig.1. Peripheral intravenous evolution: Tiered pyramid with product category and their features (right) and benefits (left). Both ported and straight peripheral intravenous catheters have evolved to include safety features which protect the health care worker from sharps and blood exposure injury and patient from many complications associated with invasive venous access.

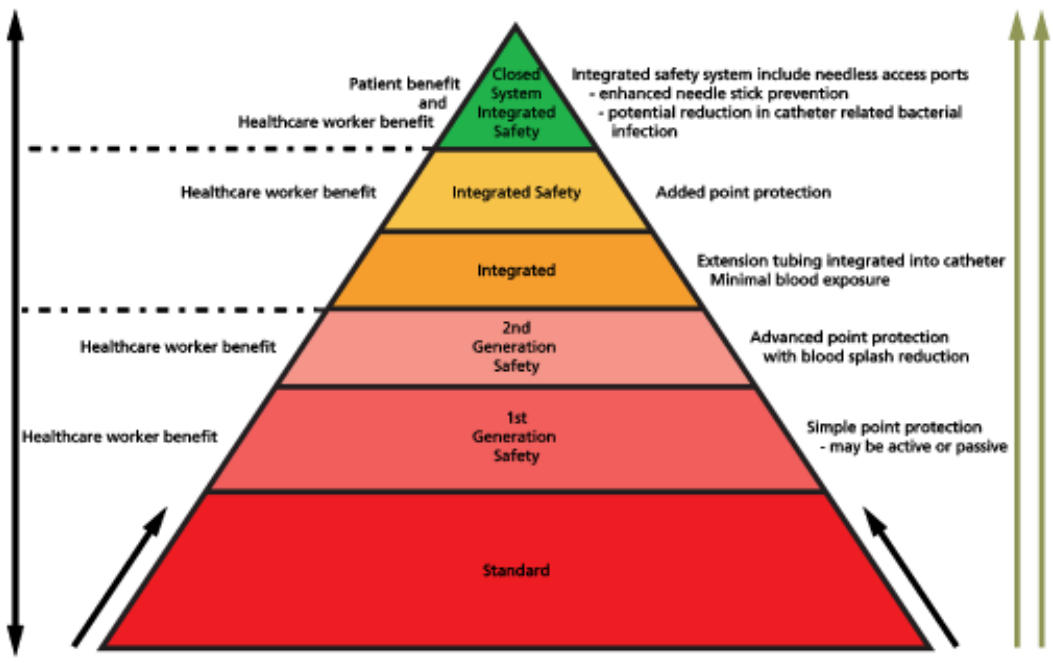

injections. These are called 'ported' IVCs and are particularly popular in northern European countries. IVCs without these ports are called 'straight' IVCs. Manufacturing data show that such cannulae are commonly used in southern Europe and in the USA. Some peripheral IVCs are fitted with mechanisms that protect against accidental needlestick injury (NSI). These are called 'safety' catheters. Other peripheral IVCs come with built-in extension tubing and are called 'integrated' devices. Some have valves that allow access with needleless devices but prevent blood leakage or pathogen entry. These are called 'closed' systems. There are also IVCs with combinations of these features; for example, a safety, integrated, closed catheter (6) has recently been introduced to the market.

\section{Risks and solutions}

Despite the engineering feats that have driven the evolution of IVC, there are still risks to their use that are not altogether different from those faced in the 1950s by Massa (4) and colleagues. In order to penetrate veins, an IVC must use a sharp needle, which raises the risk of NSIs. Given the human immunodeficiency virus (HIV) epidemic and the prevalence of hepatitis sub-types transmitted parenterally, every NSI in the health care setting risks transmitting a deadly pathogen. A surprising number of NSIs occur after use, during the disposal process, and the victims are often not the user but a downstream person such as the cleaning staff. Even patients can be victims. Often, NSIs are not reported, especially when there is a fear of repercussions such as job loss or sanction (7).
In 2000, President Clinton signed into law a bill requiring the use of safety sharps devices in health care settings in the USA (8). In 2006, a similar legislation was passed in Spain (9) and a directive was issued in Germany (10). Today, a variety of manufacturers provide safety IVCs for the European market.

IVCs reside, usually for days on end, in close proximity to the vein walls. The IVCs invariably irritate endothelial cells lining the vein walls by rubbing up against them and/or by exposing them to the variable $\mathrm{pH}$ and osmolarity of the substances infused through them. Furthermore, these 'foreign objects' serve as magnets for platelets and fibrinogen, which produce a biofilm that can promote thrombosis, embolism and bacterial growth. Redness, pain at the insertion site, blocked or slow-flowing catheters and phlebitis are among the everyday consequences of the cohabitation of catheters with veins. At times the risk can become life-threatening with bacteraemia, candidaemia or fungaemia resulting from an infected catheter. Today, the polyvinyl chloride of Massa's day has been replaced by materials such as Vialon ${ }^{\mathrm{TM}}$ (BD, NJ, USA) and Ocrilon ${ }^{\mathrm{TM}}$ (Smiths Medical MD, Inc., St Paul, MN, USA) (forms of polyurethane), which are significantly less thrombogenic and decrease the risk of phlebitis and other infectious complications (11-15).

Experienced inserters usually bring a supply of gauze to the bedside because intravenous insertion has traditionally been associated with blood leakage. Conventional peripheral catheters confirm vein entry by the presence of blood flowing into a 'flashback chamber', but in most of these devices the blood does not stop there. It continues along the 


\section{K. W. Strauss et al.}

channel left by the exiting stylet and then drips, leaks or splashes out of the end of the catheter. Hence the need for gauze to absorb the blood and limit exposure for the user or reduce soiling of the patient or linens. This exposure represents a risk to the inserter, which can be as significant as an NSI if blood reaches a break in the skin or a mucous membrane. A study examining the hands of health care workers (HCWs) for small wounds and scratches found that $57 \%$ of the hands of nurses showed small, acute or chronic skin injuries (16).

Only $1 / 10,000 \mathrm{ml}$ of infected plasma is required for hepatitis B virus (HBV) transmission (17). This amount is easily exceeded by the volume of blood that drips from the average catheter or even the amount that remains in the stylet. Furthermore, $\mathrm{HBV}$ is stable in dried blood for up to 7 days. Therefore, blood dripped on linen represents a potential risk to a multitude of people in the health care setting (17). Recently, an IVC (Venflon Pro Safety $^{\mathrm{TM}}$, BD) has been developed that reduces the risk of dripping or splashing, thus reducing the risk of such exposure and providing protection against bloodborne pathogens.

\section{Types of IVC in the European market}

\section{Standard devices}

These IVCs are the base products in the marketplace, with the broadest range in both brand and quality. A shrinking number of such catheters in Europe continue to use Teflon as a primary catheter material. Newer, more vein-friendly materials such as polyurethane are gradually replacing Teflon. Vialon $^{\mathrm{TM}}$, a biomaterial made of polyurethane, has been proven to increase indwell time (length of time a device is left implanted in a patient) and reduce the risk of phlebitis (11-15). Even though the variation in quality from one device to another may be substantial, these devices have tended to become ever more commoditised, to the potential detriment of patients. Today, procurement decisions are often made with price as the major discriminator.

Within the category of standard devices, one also finds winged vs. non-winged catheters. The wing was originally a feature used to assist with insertion, but its main utility today appears to be in helping in the fixation of the catheter to the skin after insertion. Furthermore, there are neonatal devices, which are usually shorter and have a smaller diameter (i.e. increased gauge) and also come in winged and non-winged varieties. Finally, there are winged needle sets (e.g. 'butterflies'), which are commonly used in infants where scalp vein access is common.

\section{Safety devices}

The first safety device appeared in the European market in 1990. Such devices protect the user from sharps injury by retracting the needle, covering its tip after use or using some other mechanism. Today, the safety catheter share of the market varies from country to country but remains relatively low, despite safety devices having been proven to reduce the rate of NSIs in HCWs to nearly zero in some studies (18-19). Conversion from standard to safety devices is expected to accelerate as governments increasingly mandate that health care institutions use safety devices to limit the risk of disease transmission from NSIs. The safety directive recently passed in Germany (10) and legislation now in force in Spain (9) are expected to accelerate the conversion to safety in these countries.

Currently, safety devices exist in two forms, active and passive. Passive devices imply that the safety mechanism is activated during routine performance of the procedure (i.e. the user does not need to intervene for the mechanism to deploy), whereas active implies that a distinct and separate action is required by the user to deploy the pointprotection mechanism.

\section{'Bloodless' safety devices}

We draw a distinction between first- and secondgeneration safety products (Fig. 1). This is based on the incorporation, in the latter, of additional design features to reduce the risk of infectious disease transmission from blood splashing and dripping during the insertion and disposal procedures.

\section{Integrated devices}

Integrated devices define the next tier of sophistication (Fig. 1). 'Integration' refers to the fixed addition of extension tubing to a standard device. As with simple non-integrated devices, this class of device has evolved to incorporate protection against accidental blood exposure and to reduce excess manipulation, and consequently premature device failure, at the insertion site. 


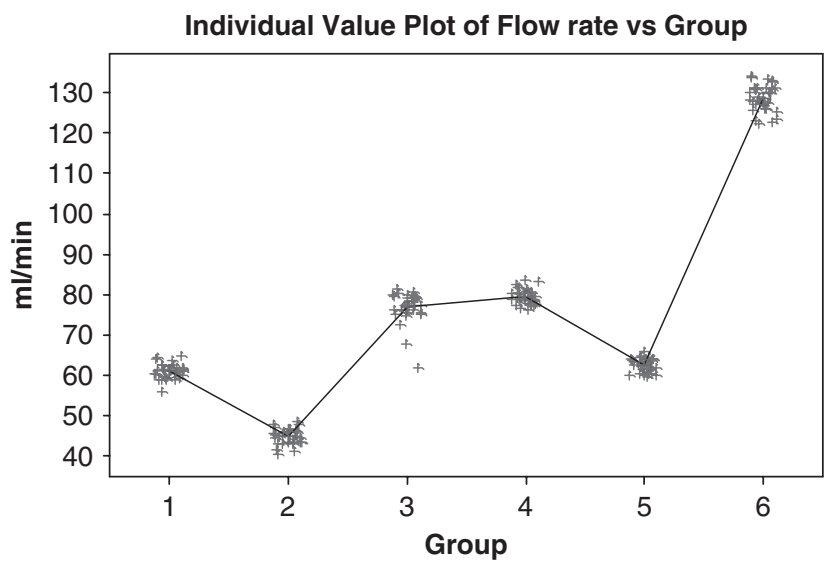

Results of 30 tests/group; in each group the height difference between bag and catheter tested was $1000 \mathrm{~mm}$. No pressure was used, except in group 3 where a pressure of $100 \mathrm{~mm} \mathrm{Hg}$ was applied.

Groups

1. $18 \mathrm{G} \times 32 \mathrm{~mm}$ Nexiva + IV set BBraun + glucose $5 \%$

2. $18 \mathrm{G} \times 32 \mathrm{~mm}$ Nexiva + IV set BBraun + artificial blood Gelofusine

3. $18 \mathrm{G} \times 32 \mathrm{~mm}$ Nexiva + IV set BBraun + artificial blood Gelofusine

4. $18 \mathrm{G} \times 32 \mathrm{~mm}$ Venflon Pro $+10 \mathrm{~cm}$ extension + IV set BBraun + glucose $5 \%$

5. $18 \mathrm{G} \times 32 \mathrm{~mm}$ Venflon Pro $+10 \mathrm{~cm}$ extension + IV set BBraun + artificial blood Gelofusine

6. 14Gx45 mm Venflon Pro + IV set BBraun + artificial blood Gelofusine

Fig. 2. Flow rate analysis of closed system catheter (Nexiva) vs. conventional catheter with extension (Venflon Pro).

\section{Closed system, integrated safety devices}

New generation integrated devices have evolved one step further to incorporate closed, needleless access systems that offer potential patient benefit in addition to the needlepoint protection or HCW safety (Fig. 1). A 'closed' system may afford better protection against bacterial exposure than conventional 'open' ports and, because blood does not naturally escape from the catheter hub, these devices further minimise the risk of exposing the clinician to blood during the insertion procedure. These devices may reduce the risk to patients of developing health care-associated infections (HAI). HAIs are infections that the patient did not have on entry to the hospital, but that developed within $48 \mathrm{~h}$ of entry. HAI-fighting devices hold great promise of benefit in the era of under-funded health care systems, exhausted antibiotic armamentaria and the ever-increasing incidence of serious health care infections such as methacillinresistant Staphyloccoccus aureus (MRSA).

One of the concerns about closed, integrated catheters with their built-in extension tubing is whether they can deliver adequate flow rates. In an experiment comparing integrated and conventional catheters and involving six different configurations [glucose vs. artificial blood, pressure vs. no pressure, extension vs. no extension (on the conventional device)], we were able to show that closed, integrated catheters are able to deliver clinically appropriate flow rates, in the absence of pressure, of $61 \mathrm{ml} / \mathrm{min}$ (SD 1.9) of $5 \%$ glucose solution and $45 \mathrm{ml} / \mathrm{min}$ (SD 2.0) of artificial blood (Fig. 2, unpublished data on file, available on request from $\mathrm{BD})$. These translate into 3.66 and $2.701 / \mathrm{h}$, respectively, rates that far exceed the clinical requirements of all but the most extreme volume-loss conditions.

\section{Current European market}

The peripheral intravenous market in Europe can be stratified into three broad tiers (Fig. 1). The first tier is comprised of standard catheter devices and forms the largest segment of the market. The second tier is comprised of integrated devices. The third tier consists of the new generation, closed system, integrated devices, which protect both patient and HCW.

Each tier may be further sub-divided into safety and non-safety variants, while the first tier is additionally split into ported and non-ported categories (Fig. 1).

\section{Market forces and future evolution}

Growth in the overall peripheral intravenous market in Europe, about 5\% a year over the near term, is expected to be driven by an ageing population, and the resultant increase in numbers of people susceptible to illness (especially cancer) and hospitalisation. The increase in safety devices will be driven by legislative as well as demographic, disease and individual factors. Recently, the Committee on Employment and Social Affairs of the European Commission submitted to the EU Parliament a motion for a resolution on protecting EU workers from NSIs (20). It would require that 4 years after passage, European health care institutions would have to certify that they are using safety devices wherever there is a risk of sharps injury (20). This would put Europe in line with USA on this type of legislation. Today, only Spain (9) and, to some extent, Germany (10) have binding USA-type legislation.

As in all developed countries, an ageing European population will require more hospitalisations and the use of more peripheral IVC for complex treatment regimens. The anticipated rise in cancer with the need to infuse chemotherapeutic agents will require catheters that help 


\section{K. W. Strauss et al.}

prevent infection, infiltration and extravasation. This demographic factor, along with the rise of HAIs and 'super bugs' like MRSA, will promote the use of integrated, closed, safety intravenous systems.

Another factor driving the conversion to such devices may be increased awareness of individual cases of HCWs who have been injured or worse by conventional devices. Recently, a British physician, Dr Peter E. Jensen, died as a result of an accidental NSI that occurred 30 years ago (21). He had contracted HBV in 1976 after taking a blood sample from a patient. The HBV led to liver cancer, which was the immediate cause of his death. Media attention on several high-profile cases of HIV transmission to HCWs in San Francisco in the 1990s helped drive the case for a safety law in the USA. Similar forces are at work in Europe.

Table 1

Requirements for a safety medical device as per Spanish law (8).

\begin{tabular}{|c|c|c|}
\hline $\begin{array}{l}\text { Require- } \\
\text { ment }\end{array}$ & $\begin{array}{l}\text { Issue } \\
\text { addressed }\end{array}$ & $\begin{array}{l}\text { Exact wordings (translated from } \\
\text { Spanish) }\end{array}$ \\
\hline 1 & $\begin{array}{l}\text { Purpose of } \\
\text { device }\end{array}$ & $\begin{array}{l}\text { 'The ultimate aim of the safety device } \\
\text { must be the elimination of risk from an } \\
\text { accidental biologic exposure' }\end{array}$ \\
\hline 2 & $\begin{array}{l}\text { Ensuring } \\
\text { patient safety }\end{array}$ & $\begin{array}{l}\text { 'The safety device must never } \\
\text { compromise patient safety' }\end{array}$ \\
\hline 3 & $\begin{array}{l}\text { Irreversibility } \\
\text { after activation }\end{array}$ & $\begin{array}{l}\text { 'The safety mechanism must activate } \\
\text { irreversibly. The device must not be } \\
\text { able to be deactivated. It must } \\
\text { maintain its protective function until } \\
\text { disposed off' }\end{array}$ \\
\hline 4 & $\begin{array}{l}\text { Timely } \\
\text { activation }\end{array}$ & $\begin{array}{l}\text { 'The activation of the safety } \\
\text { mechanism on the device should } \\
\text { coincide with the completion of the } \\
\text { clinical procedure for which it was } \\
\text { used; for example, as soon as the } \\
\text { needle has been withdrawn from the } \\
\text { puncture site' }\end{array}$ \\
\hline 5 & $\begin{array}{l}\text { Integrated } \\
\text { safety }\end{array}$ & $\begin{array}{l}\text { 'The safety mechanism should be } \\
\text { integrated into the device, and not be } \\
\text { merely an accessory to it' }\end{array}$ \\
\hline 6 & $\begin{array}{l}\text { One-hand } \\
\text { activation }\end{array}$ & $\begin{array}{l}\text { 'Activation of the safety mechanism } \\
\text { should be possible with one hand, in } \\
\text { situations where this is necessary' }\end{array}$ \\
\hline 7 & $\begin{array}{l}\text { Activation } \\
\text { signal }\end{array}$ & $\begin{array}{l}\text { 'Activation of the safety mechanism } \\
\text { should be signaled to the user by } \\
\text { auditory, tactile or visual means' }\end{array}$ \\
\hline 8 & Ease of use & $\begin{array}{l}\text { 'The safety device should be easy to } \\
\text { use and require little change in } \\
\text { technique on the part of the user' }\end{array}$ \\
\hline 9 & $\begin{array}{l}\text { Reliability and } \\
\text { fitness for use }\end{array}$ & $\begin{array}{l}\text { 'The safety device must be reliable } \\
\text { and efficient in accomplishing the } \\
\text { purpose for which it was designed' }\end{array}$ \\
\hline
\end{tabular}

\section{Legal requirements for safety catheters}

At this writing, only two countries, USA and Spain, have laws mandating the use of safety medical devices in both public and private health care settings. In many ways, the Spanish law is more precise and proscriptive than the USA law. In Annex II of the Spanish law (9), specific requirements are laid out, which a product must meet before it can be classified as a 'safety medical device' (Table 1). Among others, these include irreversibility of the activation mechanism, integration of the mechanism with the device, inclusion of a tactile, auditory or visual signal that the device has been activated and a design that requires minimal change in procedural technique.

\section{Needs still unmet}

Despite all the progress made in preventing NSI, infection and blood exposure, most new generation IVCs still do not measure up on one or more of the following requirements:

\section{Instant blood flashback}

The earlier one sees blood flashback after penetration of the vein, the more likely one is to stop advancing and the less likely to traverse the opposite wall of the vein (transfixation). In most current catheters, blood must flow the entire length of the needle in order to reach the flashback chamber and alert the user that he/she is in the vein. This delay means that for a critical instant the inserter is 'flying blind' (in the vein but not knowing it) and risks transfixation. The earliest flashback is currently provided by notched needles, which reveal the presence of blood almost the instant the vein wall is penetrated.

\section{Perfect visibility of puncture site}

Infection prevention requires the $\mathrm{HCW}$ to observe the puncture site frequently for bleeding around the catheter or the inflammatory changes that signal phlebitis or infection. Clear visibility is provided by transparent catheter components at the patient end (e.g. transparent wings) as well as a transparent dressing. Currently, there is no totally transparent intravenous system. 


\section{Minimal pain to patient}

Intravenous canulation is a painful procedure with all current catheters. This pain can be reduced by changes in the sharpness and geometry of the needle tip, by reducing the gauge of the catheter, by the use of certain plastics and, most importantly, by the skill of the inserter. The goal of painless intravenous insertion is currently an elusive holy grail for manufacturers.

\section{Minimal infection}

Infection risk is multifactorial, depending on the catheter material, the agent and procedure used to prepare the skin, the post-insertion site care and the sterility of infusions given. Currently, IVCs account for approximately $10 \%$ of nosocomial infections in the hospital (22), and 2.7-3.7 per 1000 central IVCs and $0.2-0.5$ per 1000 peripheral IVCs become infected. In average-sized hospitals (500 beds) using 60,000 peripheral IVCs per year one would expect up to 30 bloodstream infections in a year due to the peripheral IVC itself (22).

\section{Minimal thrombotic risk}

This depends on many of the same factors as the infection risk. There are some innovative approaches to detect and prevent the build-up of biofilm, but none of these are in commercial use.

\section{Dynamic softening of the catheter in the vein}

Friction of the catheter tip and body against the endothelium is one of the key pathogenic mechanisms in phlebitis. Some catheter materials change their stiffness after a length of time at body temperature (i.e. inside the vein). Such catheters are less likely to cause mechanical phlebitis or to kink and obstruct; consequently, they may also have a lower infection and thrombotic risk (11-15). However, it is more difficult to draw blood back through such a catheter (not a recommended procedure due to the high potential for creating haemolysis, but, unfortunately, one often performed).

\section{Total elimination of blood exposure to the user}

An IVC, which was totally closed would prevent the escape of blood into the environment, provide protection against mucocutaneous exposure to blood of the user and eliminate the risk of microorganism entry into the patient. Unfortunately, catheter systems are made to provide intermittent access of drugs and other fluids to the patient, and this, by definition, requires opening and closing of the system. Permanently closed systems are difficult to conceive of at the moment.

\section{Multi-lumen port access}

Such catheters, when used peripherally, provide many of the advantages of a central venous catheter. Multiple ports can be provided by including an additional port on the catheter itself (the 'ported' catheters used frequently in Europe), by the attachment of a stop cock or by the use of extension tubing (either attached or integral to the catheter) with multiple ports. Unfortunately, the higher the number of ports, the higher the risk of blood escape or microbial entry.

Needleless access to ports

Such catheter systems are more 'closed' to bacterial entry than conventional ones and reduce needlestick risk.

\section{Simple to dress, difficult to snag}

The optimal catheter would have a completely flat profile allowing the dressing to cover it smoothly without wrinkling or binding. Such a covering would be less likely to catch on objects in the environment or to come loose between dressings and would reduce the friction of the external catheter body on the patient's skin to a minimum.

\section{Conclusion}

The European peripheral intravenous market is currently being served with a range, which varies from low-end conventional to high-end integrated, closed safety devices (Fig. 1). As one mounts this pyramid, the costs inevitably increase but so do safety and clinical values for both users and patients. Several forces are driving the market 'up the pyramid', including legislative, clinical and media factors. More study is needed to determine the degree to which the benefits to both user and patient compensate for the additional cost and training that these new devices entail. Manufacturers should not assume that the summit has been reached with their latest offerings, but should focus on the still-unmet needs in designing future solutions. 


\section{K. W. Strauss et al.}

\section{Acknowledgements}

Two of our authors (K. S., R. O.) are medical directors for BD, a manufacturer of IVCs. A. A. J. v. Z. has not received any financial support from BD for writing this paper, research, travel or lecturing.

\section{References}

1. Gabriel J, Bravery K, Dougherty L et al. Vascular access: indications and implications for patient care. Nurs Stand 2005; 19 (26): 45-52.

2. Rivera AM, Strauss KW, van Zundert A et al. The history of peripheral intravenous catheters: how little plastic tubes revolutionized medicine. Acta Anaesthesiol (Belgium) 2005; 56: $271-82$

3. Rivera AM, Strauss KW, van Zundert A et al. Matching the peripheral intravenous catheter to the individual patient. Acta Anaesthesiol (Belgium) 2007; 58: 19-25.

4. Massa D. A plastic needle. Anesthesiology 1951; 12: 772-3.

5. Cosnett JE. Before our time: the origins of intravenous fluid therapy. Lancet 1989; 4: 768-71.

6. Van Zundert A. New closed IV catheter system. Acta Anaesthesiol (Belgium) 2005; 56: 283-5.

7. Trim JC, Adams D, Elliott TS. Healthcare workers' knowledge of inoculation injuries and glove use. Br J Nurs 2003; 12: $215-21$.

8. Occupational Safety and Health Administration. Occupational exposure to blood borne pathogens: needle sticks and other sharps injuries; finale rule. Fed Reg 2001; 66: 5317.

9. Orden 714/2006, Boletín Oficial de la Comunidad de Madrid. Jueves, 26 de Febrero del 2006, pp. 13-14.

10. German Technical Rules for Biologic Devices (BGR/TRBA 250 "Biologische Arbeitsstoffe im Gesundheitswesen und der Wohlfahrtspflege"), 2005.

11. Gaukroger PB, Roberts JG, Manners TA. Infusion thrombophlebitis: a prospective comparison of 645 vialon and teflon cannulae in anaesthetic and postoperative use. Anaesth Intensive Care 1988; 16: 265-71.

12. Stanley MD, Meister E, Fuschuber K. Infiltration during intravenous therapy in neonates: comparison of teflon \& vialon catheters. South Med J 1992; 85: 883-6.

13. Jaquot C, Fauvage B, Bru JP et al. Effect of type of material on thrombophlebitis risk with peripheral venous catheters. Ann Fr Anesth Réanim 1989; 8: 3-7.
14. Maki JM, Ringer M. Risk factors for infusion-related phlebitis with small peripheral venous catheters. Ann Intern Med 1991; 114: 845-1.

15. McKee JM, Shell JA, Warren TA et al. Complications of intravenous therapy: a randomized prospective study vialon vs teflon. J Intraven Nurs 1989; 129: 288-95.

16. Saghafi L, Raselli P, Francillon C et al. Exposure to blood during various procedures: results of two surveys before and after the implementation of universal precautions. Am J Infect Control 1992; 20: 53-7.

17. Manns MP, Wedemeyer H, Meyer S et al. German Society for Alimentary Metabolic Disorders; hepatitis competence network. Diagnosis, progression and therapy of hepatitisB-virus infection - results of an evidence based consensus conference of the German society for alimentary metabolic disorders and in cooperation with the hepatitis competence network. Z Gastroenterol 2004; 42: 677-8.

18. Adams D, Elliott T. Impact of safety needle devices on occupationally acquired needle stick injuries: a four-year prospective study. J Hosp Infect 2006; 64: 50-5.

19. Mendelson MH, Short LJ, Schechter CB et al. Study of a needleless intermittent intravenous-access system for peripheral infusions: analysis of staff, patient, and institutional outcomes. Infect Control Hosp Epidemiol 1998; 19 (6): 401-6.

20. Protecting European healthcare workers from blood borne infections due to needlestick injuries. 2006/2015 (INI). http: / / www.europarl.europa.eu/oeil/ file.jsp?id=5303952

21. 'GP dies from injury 30 years on', The Times (London), December 9, 2006, Home News, p. 24.

22. Maki DG, Kluger DM, Crnich CJ. The risk of bloodstream infection in adults with different intravascular devices: a systematic review of 200 published prospective studies. Mayo Clin Proc 2006; 81: 1159-71.

Address:

Prof. Dr André A. J. van Zundert

Department of Anaesthesiology, ICU and Pain Therapy

Catharina Hospital, Brabant Medical School

Michelangelolaan 2

Eindhoven, 5623 EJ

The Netherlands

e-mail: zundert@iae.nl 